船体構造特別講演会における講演

昭和 45 年 9 月初め第 3 回国際船体構造会議が東京で開催され各国の船体構造関係の権威が多数来日され た機会を利用して, 船体構造特別講演会が 9 月 4 日船舶振興ビル 10 階会議室で開催され J.H.Evans, J.B. Caldwell および J.Moe 3 氏の特別講演が行われましたが，本文はその講演を収録したるのであります。

\title{
Optimizing Ship Structural Design Through the Choice of Materials
}

\begin{abstract}
By J. Harvey Evans*
(Presented before the Special Lecture Meeting arranged by the Society of Naval Architects of Japan on September 4th, 1970, Tokyo, Japan)
\end{abstract}

\section{Introduction}

Preliminary design decision are probably most notable for the limited information on which they must be based. And yet the nucleus about which the design is ultimately developed must be corretly identified at that early stage or subsequent efforts fail to achieve their purpose. Not only may they be fruitless but costly as well. Furthermore, the efficiency with which one converges on this nucleus is also of interest for its saving of time and manpower.

In ship structural design, hull steel weight and the cost of construction are both acknowledged to be important design considerations which, if each ruled independently of the other, would lead to differing desing solutions. The true optimum would undoubtedly involve some compromise between the two, depending upon an analysis of the ship's operation. For each contending structural material, supposing it to be used exclusively, the same compromise would have to be made and then the best among the compromises chosen. Of course, a still higher order of complexity is introduced by allowing for a several materials in several locations within the same structure. For each of these there must be an optimal combination of framing systems, optimal frame spacings, optimal distributions of the materials and of each of them within its own confines. And certainly, the list could be extended.

With estimates of cost and weight both equally critical to the decision making process there seems no alternative but to determine certain control scantings explicitly for each design possibility, even though the task is great. By no other means can any but the most gross parametric variations of the structure be taken into account. There is reason to expect that the midship section properties adequately reflect the character of the total hull and will serve to discriminate between one solution and another. Furthermore, the midship section structure is responsive to changes in most of the design parameters.

The studies reported on here were for the purpose of developing this proceeding in detail and proceeding with whatever refinements were most necessary to improve our structural design capability, to demonstrate potential benefits from using a variety of materials, and to make more readily available a practical and quantitative means of arriving at more nearly optimum design conclusions.

\section{The Optimum Structural Design}

Although there are a number of considerations other than structural weight and cost of construction which enter into structural design decisions, it seems generally agreed that these two are the major ones. Interpolating between them for the design optimum, obviously requires a detailed analysis of a

* Professor of Naval Architecture, Massachusetts Institute of Technology, Department of Naval Architecture and Marine Engineering, U.S.A. 
vessel's intended service involving many factors of earning and expense summed over the ship's entire life. The implication is that, ideally, such an operations analysis study will have been made in each design situation and that some definite indication will be available as to where the line must be drawn between the least weight and the lowest cost structures. Conversely, by using "performance norm curves", a means is suggested so that the benefits or penalties associated with a range of structural design variation can be incorporated into an operations analysis and so help effect a solution defining the best total ship for the required service.

So, for each particular service there is a specific ship (in terms of its principal dimensions, form and internal arrangement) to which detailed findings, similar to those reported here, apply uniquely. In this case, a standard U.S.Maritime Administration “Mariner" type cargo ship $\left(528.5^{\prime} \times 76^{\prime} \times 44.5^{\prime} \times\right.$ 29.75') has been chosen to illustrate the analysis. Even though limited to a single ship, some general conclusions from such a study should also be apparent and some valuable insights gained.

\section{The Structural Midship Section}

Even if performed in the most orderly and rational way, midship section scantling calculations for one material alone involve an iterative process which may be excessively time consuming if performed manually and over a range of variables such as frame spacing. When more than one material is used, the stress level at any of the material interfaces may be more critical than at the strength deck or bottom and convergence on the ultimate design is more protracted. For these reasons, and to throughly explore all reasonable design possibilitties, automatic computation is practically mandatory.

During the past twelve years, work has been actively pursued on a growing methodology of ship structural design, especially as it relates to the midship section. Simultaineously, progress with associated computer programs has kept pace. At M.I.T., a fifth generation of such design aids is now available and, with its immediate predecessor, was used to develop the results given here.

\section{Structural Performance Norms}

Once the midship section scantlings (including transverse members) have been determined, the related weight of structure has been normalized and expressed in units of tons per foot of length.

Total costs are made up of the cost of materials, plus labor costs incurred, plus overhead or plant operation costs. Material costs are derived from the weight of material, categorized either as "plates" or rolled "shapes". Estimating labor costs was much more of a problem and, ultimately, a simple yet fairly discriminating formulation offered by a shipbuilding firm was adopted. Although rough and reflecting the practices on one particular yard, their method seems typical and its simplicity makes it compatible with the information available and commensurate with early, roughing-out cycles of design iteration associated with "preliminary" design. The overhead allowance is taken as a flat percentage of the labor costs. Total costs then also have been normalized and expressed as U.S. dollars per foot of length.

As a means of presentings from such a study in most generalized, meaningful form and most free of distortion these normalized weights and costs are "unified", that is, related to those of a base ship. In this case it was the "Mariner" as built, but with its normalized weight and cost developed by the computer program for the sake of consistency rather than values derived from actual, returned weights and costs. The base ship, although not necessarily one in existence, is a known quantity; probably conventional in framing, material and all else so that the builder is in a good position to estimate his price for it. This ship is the parent in the family of variations. As such it provides the anchor point for "performance norm curves" which are an attempt to define a locus line of optimum structural designs on a weight-cost basis, for any combination of independent variables (such as frame spacing, 
already mentioned, for one). Ultimately in the design process, it will become necessary to select the best of the applicable performation norm curves and locate where on the true optimum lies. At this point, the interdependent findings of the life cycle study will have to be consulted and they should locate the point on this representation of possible solutions above which the cost saving cannot be accepted because of excessive weight or below which the weight saving cannot be accepted because of excessive cost. Obviously, this is another operation with which the computers may be helpful.

\section{Materials}

Three grades of steel were chosen as those available in the U.S. most suitable for ship construction and covering a spectrum broad enough to show significant weight and cost changes. Their properties are given in Table 1 as well as average unit costs. The ship cross section, modeled in the classical way, is seen as a box girder with flange and web members which may be of differing materials, as indicated in Figure 1. With these steels making up the longitudinally continuous structure, nevertheless all transverse structure was assumed to be of medium steel and sized accordingly. The one exception is in the use of hypothetical materials discussed in the concluding section. With the problems of dissimilar metals in contact being well known, it appeared best to assume all structural elements to be of the same material in that investigation.

\section{Results}

The study results shown graphically in what follows were developed at two separate periods of time between which some price changes occured as indicated in Table 1. However, no radical change of conclusions should havd resulted. There was also a re-evaluation of the fabrication differential as a result of additional discussion with shipbuilders. This differential is a ratio, with medium steel as the

Table 1. Steel Characteristics

\begin{tabular}{|c|c|c|c|}
\hline \multirow[t]{2}{*}{ Standard designation } & $\begin{array}{l}\text { Medium Steel } \\
\text { (MS) }\end{array}$ & $\begin{array}{c}\text { High Strength Low } \\
\text { Alloy Steel } \\
\text { (HTS) }\end{array}$ & $\begin{array}{c}\text { High Yield Strength } \\
\text { Alloy Steel } \\
(\text { HY) }\end{array}$ \\
\hline & ABS Class A, B, C & $\begin{array}{l}\text { ASTM A } 242 \\
\text { (normalized) }\end{array}$ & ASTM A 517 \\
\hline Designator (in Figure) & 1 & 2 & 2 \\
\hline $\begin{array}{l}\text { Ultimate tensile strength } \\
\sigma_{\mathrm{ult}}, \mathrm{psi}\end{array}$ & 60,000 & 70,000 & $115 / 135,000$ \\
\hline $\begin{array}{l}\text { Minimum yield strength } \\
\sigma_{Y}, \text { psi }\end{array}$ & 32,000 & 50,000 & 100,000 \\
\hline \multicolumn{4}{|l|}{ Study I (Fall 1965) } \\
\hline Plate cost, average, cents/lb & 6.5 & 11.0 & 17.0 \\
\hline Shape cost, average, cents/lb & 6.5 & 9.0 & 16.0 \\
\hline Fabrication differential & 1.0 & 1.0 & 1.10 \\
\hline Labor rate, dollars/hour & & 3.00 & \\
\hline Overhead, $\%$ of labor cost & & None included & \\
\hline Figure numbers applicable & & 2,3 and 4 & \\
\hline \multicolumn{4}{|l|}{ Study II (Fall 1969) } \\
\hline $\left.\begin{array}{l}\text { Plate cost, average, cents/lb } \\
\text { Shape cost, average, cents/lb }\end{array}\right\}$ & 7.5 & 10.0 & 17.2 \\
\hline Fabrication differential & 1.0 & 1.05 & 1.20 \\
\hline Labor rate, dollars/hour & & 3.80 & \\
\hline Overhead, $\%$ of labor cost & & 100 & \\
\hline Figure numbers applicable & & $5,6,7,8$, and 9 & \\
\hline
\end{tabular}




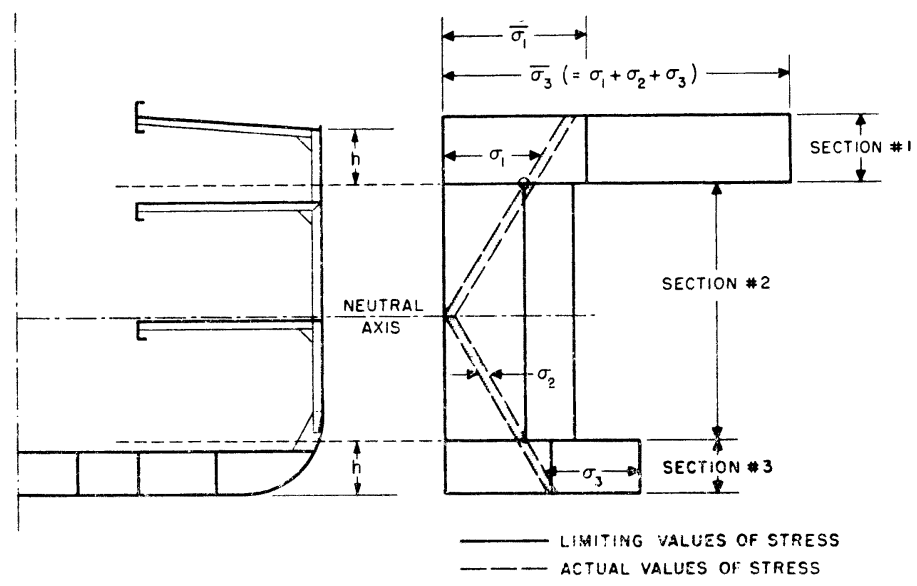

DESIGN STRESS CRITERIA

Fig. 1.

base, which seeks to account for the fabrication cost increment such as might be involved in the construction of an identical structure supposing it to be built of another material. For convenience here, it is usually stated as a sequence of ratios for the three steels of the study, in order of increasing strength.

\section{Preliminary Investigations}

Figure 2 comes about from an attempt to sense the range of normalized weights and costs which might be of interest and to test the sensitivity of results of several of the more important variables. It deals only with the cases of longitudinally continuous material fabricated exclusively of one after another of the three steels. However it does assess quantitatively the relative merits of framing

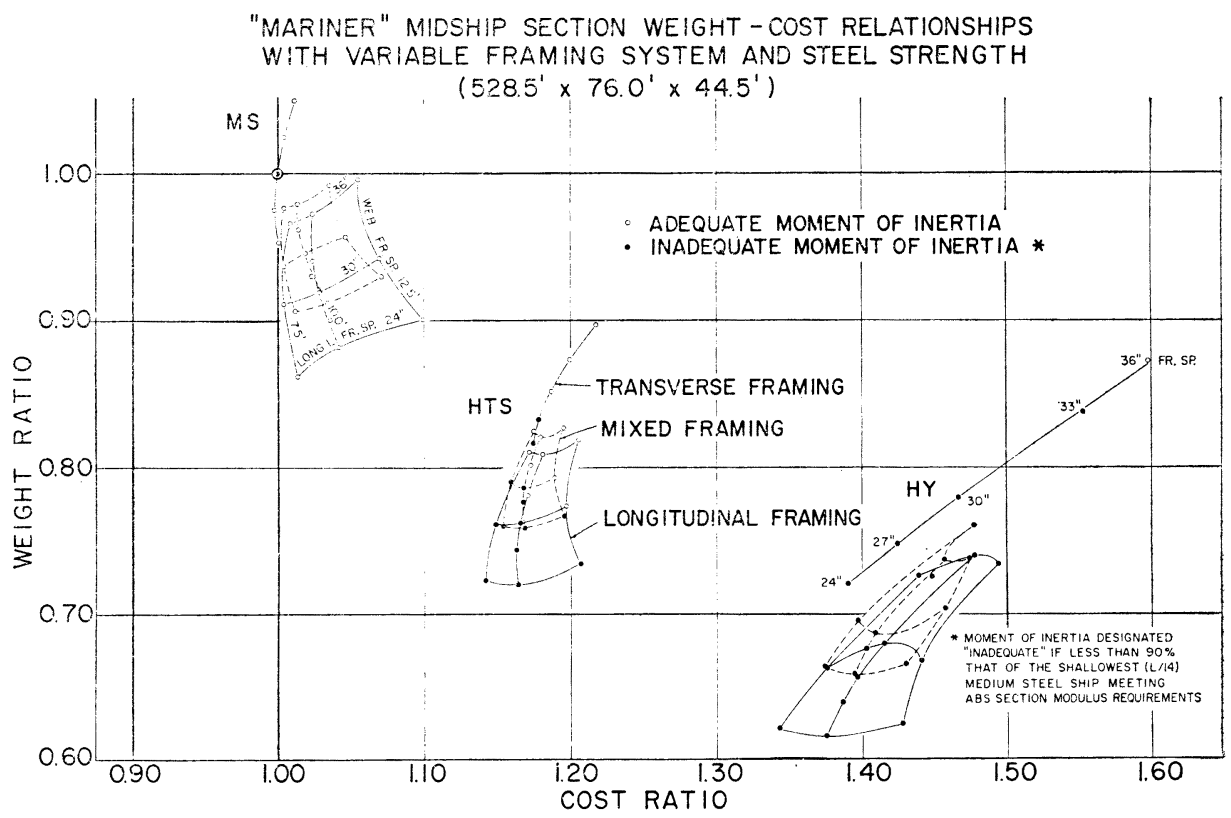

Fig. 2. 
system and frame space changes as well as the gains and losses associated with each of the steels.

A clear preference for longitudinal framing over transverse framing or the usual mixture of the two is exhibited throughout. With longitudinal framing, another notable feature is how striking the effect of web frame spacing on costs and how little its effect on weights. On the other hand, the longitudinal spacing affect the weights very greatly here and the costs much less so. At the root of this is the labor cost which continues to rise with increase of web frame spacing, unlike its normal behavior with the lighter framing.

In the design methodology followed by the computer, all scantlings, individually or for the total ship, are based upon stress or instability criteria. An average hull stiffness criterion is still a matter of uncertainty although the classification societies do prescribe limiting minimum values. The reference points on Figure 2 are coded to indicate which structures satisfied the requirement then enforced by the American Bureau of Shipping (1967) and which did not. For the great majority of cases using high strength steels, additional strength and structural weight would be required solely to meet the stiffness standard so it is important that it be established on firm and rational grounds.

When an orderly progression is followed, mixtures of the three steels used in all assortments of flange and web locations produce a family of polygons such as Figure 3 exhibits for the transverse framing case. Of the 27 possible steel-location combinations many are foolish, without doubt; to what extent can be seen in the figure. The "performance norm" which bounds the best of the combinations here is but one of numerous such possibilities.

Figure 4 is a composite of curves similarly derived for longitudinal and mixed framing in addition to that for transverse framing from Figure 3. For insight into the effect of ship proportions both a shallow and deep hull with mixed framing were also considered. With these variants in principal dimensions, the product of beam and depth was held constant so that the dimensions for the shallow ship were $88^{\prime} \times 38.5^{\prime}$ and for the deep ship $65^{\prime} \times 52^{\prime}$ whereas for the Mariner they are $76^{\prime} \times 44.5^{\prime}$. To all intents and purposes, the same seven steel combinations invariably define the performance norm curves. These are summarized in Table 2. For subsequent investigations only these seemed worthy of calculation.

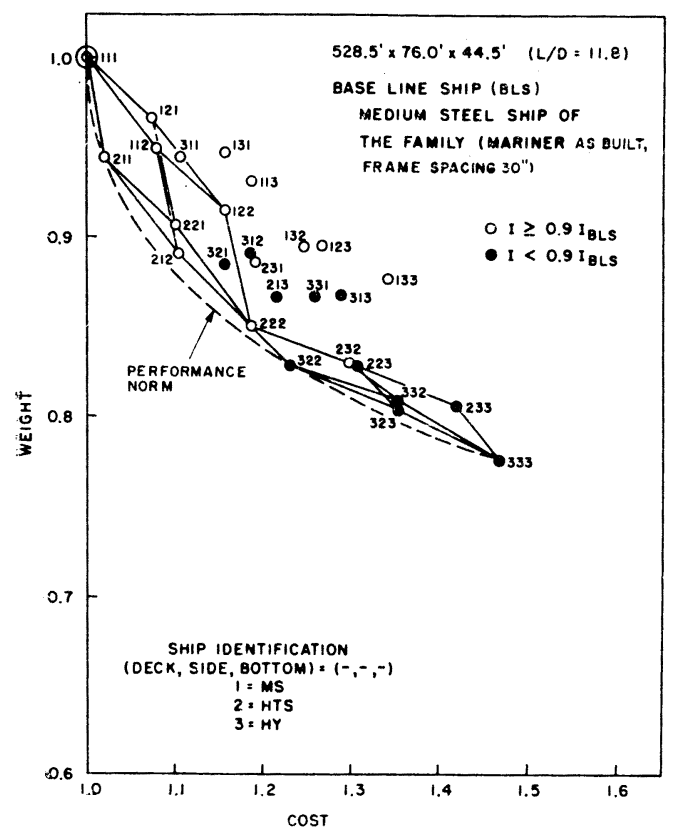

Fig. 3

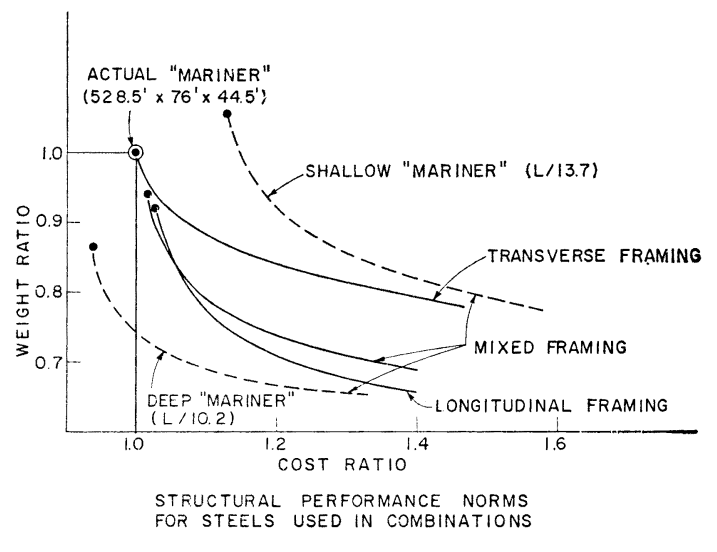

Fig. 4 
Table 2. Performance Norm Solutions, Material Combinations

\begin{tabular}{c|l|l|l|l}
\hline \hline No. & $\begin{array}{c}\text { Main } \\
\text { Deck }\end{array}$ & $\begin{array}{c}\text { Sides and } \\
\text { Lower Decks }\end{array}$ & $\begin{array}{c}\text { Bottom and } \\
\text { Inner } \\
\text { Bottom }\end{array}$ & Designator* \\
\hline 1 & MS & MS & MS & 111 \\
2 & HTS & MS & MS & 211 \\
3 & HTS & MS & HTS & 212 \\
4 & HTS & HTS & HTS & 222 \\
5 & HY & HTS & HTS & 322 \\
6 & HY & HTS & HY & 323 \\
7 & HY & HY & HY & 333 \\
\hline
\end{tabular}

* The number " 1 " signifies MS, the number "2" HTS, and the number " 3 " HY.

\section{Frame Spacing}

The exploratory studies summarized graphi... cally in Figures 3 and 4 were for fixed frame spacings : 30 inches for transverse and longitudinal frame spacings and 10 feet for web frame spacings. Refinement of performance norm curve definition demanded closer spacing for high strength steels in order to realize their full strength potential. For the transverse system of framing, as adopted in the actual "Mariner", this frame spacing question and several others were selected for closer exami-

nation. On the evidence of Figure 5, the transverse frame spacing had best be reduced to as little as $21^{\prime \prime}$ if the high yield steel is extensively used. Figure 10 indicates the extent to which both a hign strength of material and a low elastic modulus call for a frame space reduction. On the other hand, from Figures 8 and 9 it is clear that an increase of ship section modulus or relocating the strength deck at a lower level both are likely to call for an increase if frame spacing.

\section{Interface Location}

An equal strength theory of optimum design would indicate that at one point in each material of construction the appropriate maximum allowable stress for that material should be reached. Based on primary bending stress only, as in this conceptual model, this means that simultaneously at all material interfaces and/or at extreme fibers, one or the other of the materials concerned should always be stressed to its utmost. From Figure 1, it may be deduced that if interfaces are to be located in accord with this principle, their height must be a function of the allowable stresses, $\bar{\sigma}_{1^{\prime}}$ of the adjacent materials.

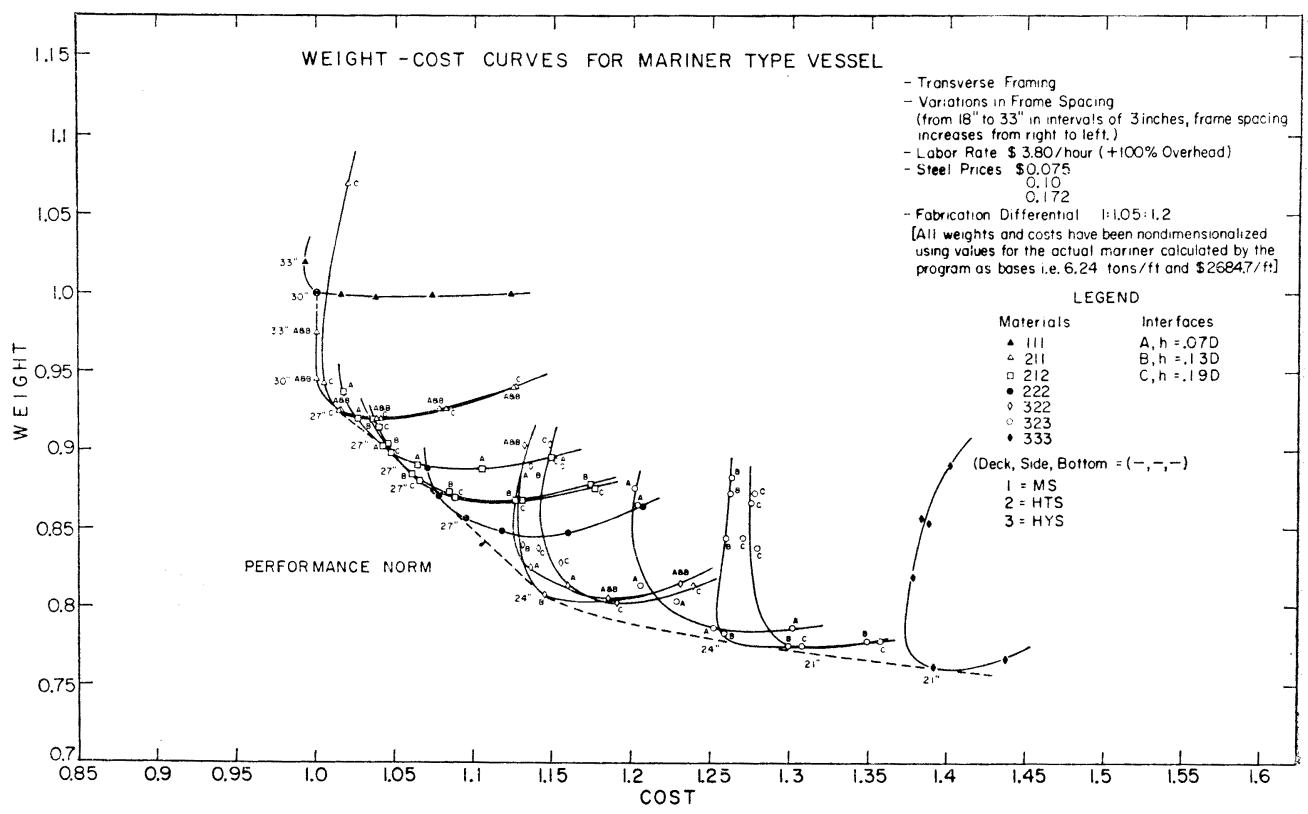

Fig. 5 
If the neutral axis is assumed to be at the half depth, $D / 2$, and the vessel upright, the distance of either interface from top or bottom, $h$, is dependent upon the allowable stress of the weaker material, $\bar{\sigma}_{1}{ }^{\prime}$ and the allowable stress of the stronger material, $\bar{\sigma}_{1}{ }^{\prime}$ as follows :

$$
h=\frac{D}{2}\left[1-\frac{\bar{\sigma}_{1}}{\bar{\sigma}_{1}^{\prime}}\right]
$$

For the steels of Table 1 used in combination, the resultant interface heights are $.115 D, .139 D$ and $.222 \mathrm{D}$. With these as merely first order approximations, symmetrical locations of .07 $D \cdot 13 \mathrm{D}$ and $.19 \mathrm{D}$ were chosen for a comparative investigation. As combination of MS the HY used together are not on the preferred list (Table 2) and so were not considered here, this choice of three locations was believed to afford ample opportunity to test quantitatively the effect of placing material interfaces too far from the neutral axis and, to a lesser extent, to test the reverse possibility.

Figure 5 also deals with the interface question. The typical interrelationship between the weightcost curves for differing interface locations can best be seen in the 322 and 323 steel combinations in which $h=0.13 \mathrm{D}$ is actually the best first approximation to the optimum location. The curves bear this out in fact. With interfaces too close to the neutral axis, just possibly, insignicantly lighter solutions can be found but their tendency is to higher priced, especially at large frame spacings. On the contrary, interfaces too close to the flanges are apt to lead to higher weight solutions although of lower cost, at least at the undesirable, large frame spacings.

In general, then, this results in the conclusion that the estimated optimum interface location adequately defines the performance norm but, on occasion, interface locations slightly on both sides of it may also lie close to the performance norm envelope. Indeed, among the lower strength steel combination, where the performance norm curvature is subject to sharp change, as in this instance, the several interface locations for a particular combination of steels will fully establish the norm in that area.

\section{Overhead Allowance}

Presumably it is common practice to relate overhead expenses to the cost of the labor force, but the particular percentage used and the exact formula seems subject to variation from one firm to another. To test the importance of including such a cost item, even though costs may be unified, i.e. related to a base ship, (or conversely to test the validity of neglecting it), some studies with and without an overhead allowance have been made. Alternatively, such data may also be employed to test sensitivity to fluctuations of the labor rate alone.

Although it may be slightly excessive for the shipbuilding industry, an allowance equal to the labor cost was included in those results designated "with overhead". Such a rate of $100 \%$ not only seems to be an outside figure, but allows for simple interpolation.

An average labor rate of $\$ 3.80$ per hour was assumed. Whenever overhead was to be included the rate was increased to $\$ 7.60$ per hour.

As Figure 6 attests, the unified results would not be especially sensitive to labor rate variations (except in the unlikely situation with all steels being priced qual.)

Although most of the studies in this series concerned themselves only with the standard $100 \%$ overhead allowance, it seems safe to say that general conclusions reached without the allowance and shown in Figures, 2,3 and 4 are not seriously endangered. Furthermore, although this a limited, oneship case study, it suggests that the results (when normalized) may not be very sensitive to the labor rate so that engineering design decisions may be reached in the face of the labor rate being uncertain except in the event of labor costs being substancially larger fraction of the total than is the case with steels. 


\section{Steel Prices and Fabrication Differential}

The principal intent of Figure 7, limited though it is to the transverse framing case, is to convy some impression of what savings may be made as experience with higher strength steels reduces the fabrication differential from the $1: 1.05: 1.20$ ratio believed to be representative at present.

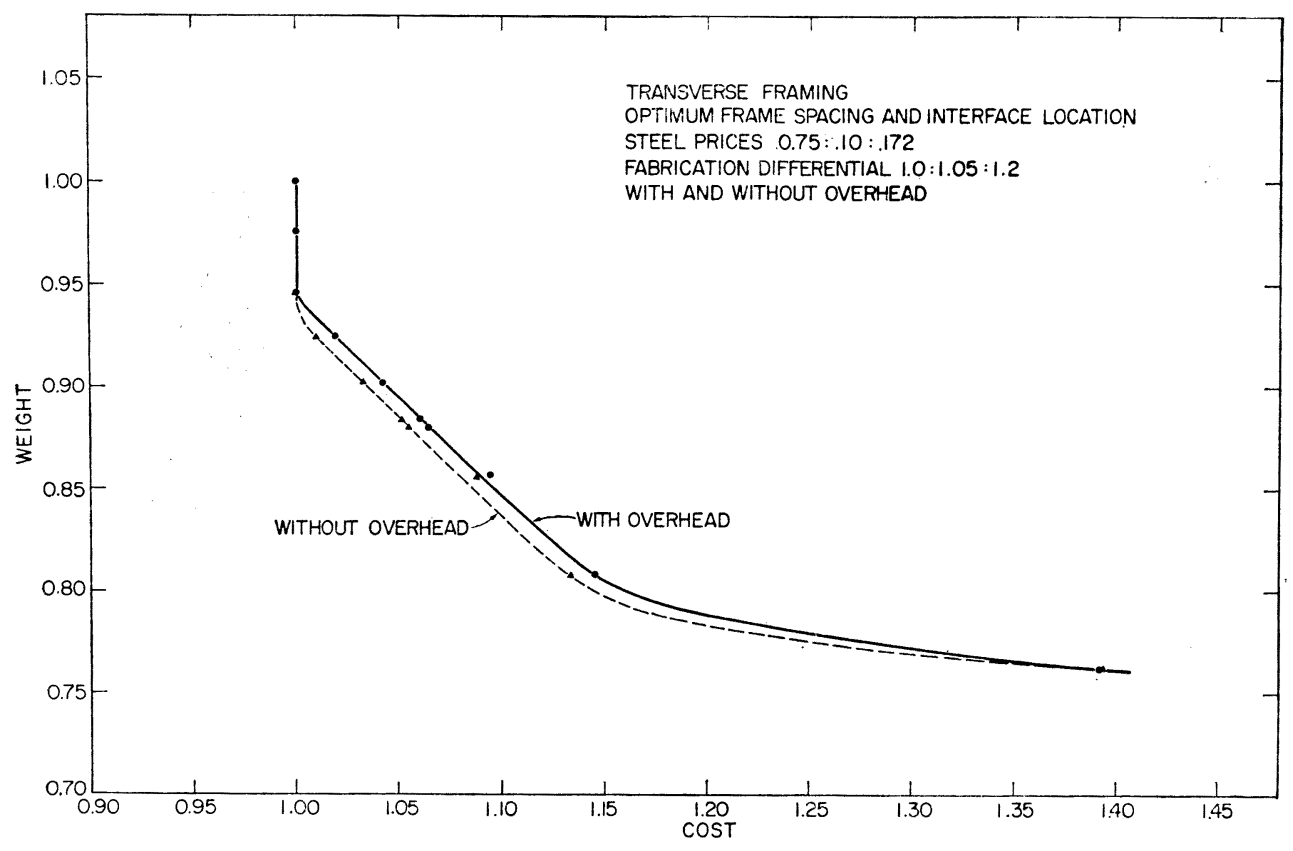

Fig. 6

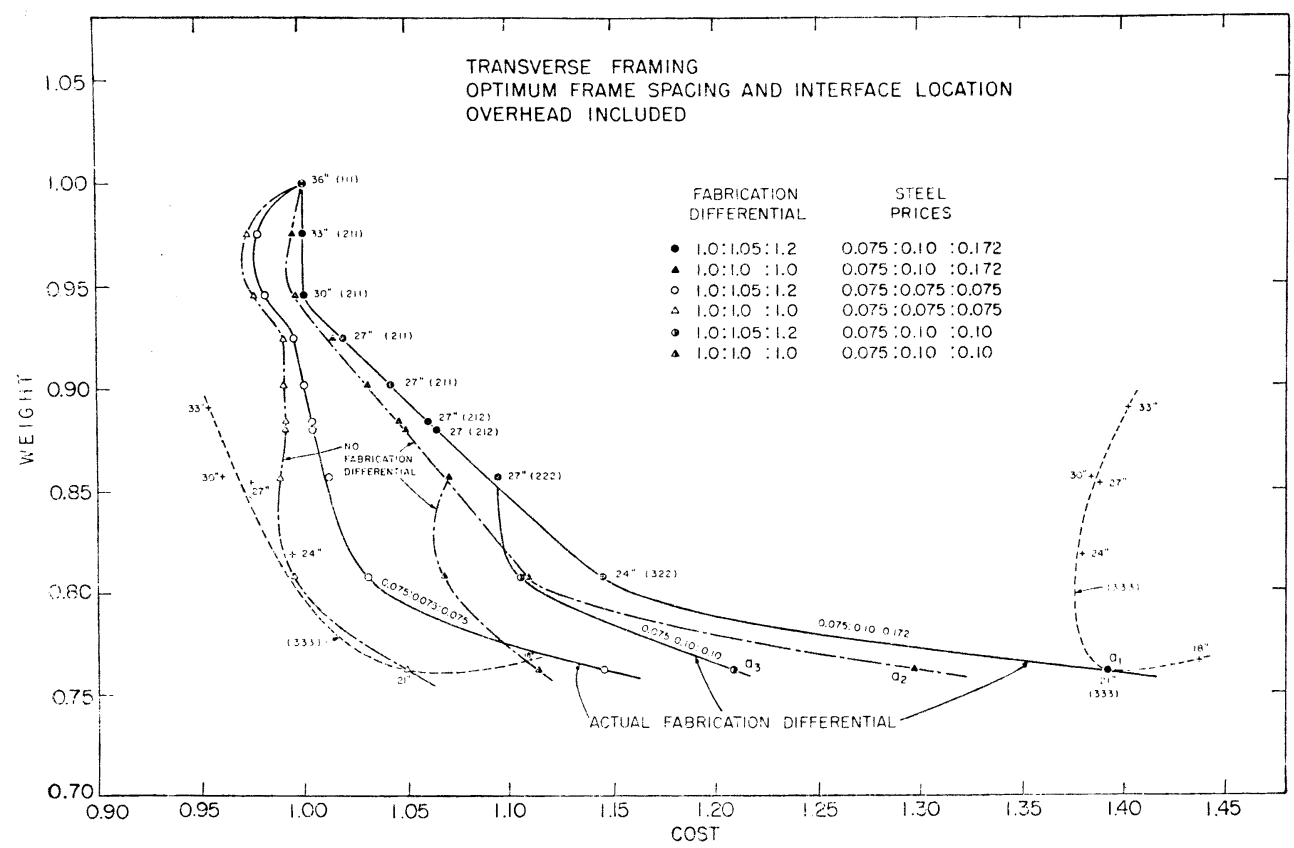

Fig. 7 
Time may also serve to reduce relatively the cost of higher strength steels or perhaps permit the use of less expensive grades which might come into being. All this being conjectural, three steel price schedules were resorted to for the investigations supporting the figure using prices now in effect in the U.S. as a base. These schedules were arrived at by first supposing that a steel with the strength characteristics of HY might conceivably be produced to sell for the same price as HTS. Carrying this one stage further reduces the prices of both HTS and HY to that of MS. At the other end of the scale is a schedule using the actual prices, viz. 7.50, 10.0 and 17.2 cents per pound. The performance norm for these prices and the actual fabrication differential again comes from Figure 5. Fanciful though the first two of these schedules may seem, they produce a meaningful set of reference lines so that changes within this price structure may be dealt with approximately by suitable interpolation.

In isolation and unrelated to the operation of a particular ship and service, general conclusions based on these price variations by themselves may be hard to see. For this reason, both the steel price scale and the fabrication costs are the subject of Figure 7. The one point commmon to all curves is the all medium steel "Mariner", as built. The next several points include increasing extents of HTS but no HY while the last two cases have increasing extents of HY but no MS. With this in mind, perhaps the three lower segments (and then the others) in each of the two trees will become intelligible.

One should be left to draw his own conclusions, as they seem justified or as his interest dictates, but beginning with the actual prices and fabrication differentials of today it seems proper to ask where the greatest economies may be found and how they may be realized. Insofar as it is credible to anticipate the availability of steels at the three strength levels all being equal in price or ease fabrication, the more striking improvement would come about with equalization of price in preference to elimination of the construction differential. This may be seen from successively relating such a point as " $a_{1}$ " exemplifying the present situation for an all-HY ship, with point " $a_{2}$ " which eliminates the fabrication differential, and point " $a_{3}$ " which reduces the price of HY to that of HTS.

For the extreme cases of all-HY in both "actual" and "equal" pricings, the complete weight-cost curves for all frame spacings are shown to illustrate the point that with any significant reduction of fabrication or material cost differentials, the optimal combination and frame spacing both may change. An obvious, if extreme, example can be seen from the figure, as it stands. Should all the steels have the same price and be equally easy to fabricate, a transversely framed "Mariner" entirely of HY with a frame spacing of $33^{\prime}$ is much to be preferred over one with an HTS deck and all else MS, even at the optimal frame spacing for that combination, which is $27^{\prime \prime}$, and with the interface location optimized. The gain, of course, is not so much in weight saving as in cost reduction, but the designer has here the means to quantify his game of choice.

\section{Costing the Moment of Inertia and Hull Stiff ness}

It is not difficult to develop midship section scantlings to meet a prescribed section modulus by the simple expedient of altering the applied bending moment while maintaining a constant allowable stress schedule appropriate to the materials involved. With the neutral axis subject to drift, however, it obviously does not follow that the moment of inertia will invariably be modified by a like factor. That is, a desired moment of inertia cannot be achieved by prescription although the section modulus may.

Added to the unpredictable displacement of the neutral axis from one steel combination or frame spacing to the next, are certain inherent undulations of the performance norm curves so that attempts to portray any completely smooth general relationship between moment of inertia and its demands of weight and cost can only be partially successful. Equally satisfactory, then, the quite servicable is a pressentation based on the section modulus itself, despite the indirectness of its relationship to the 
moment of inertia. Figure 8 is such and in it 20\% and $40 \%$ increments of section modulus are considered.

It is important that in each instance the optimal frame spacing be found.

Given any particular combination of material, it follows that with an inflated requirement for section modulus, heavier scantlings will be called for in way of strength deck and bottom. As limiting design stresses $\bar{\sigma}_{1}$ and $\bar{\sigma}_{3}$ will doubtless have remained unchanged, larger frame spacings can and should be accepted. Figure 8 bears this out; those spacings indicated being optimal in each case. From the figure it is apparent that in the all-MS ship, for a $20 \%$ excess of ship section modulus (and a comparable change in moment of inertia) about a $12 \%$ increase in structural weight and a $2.1 \%$ increase in structural weight and a $2.1 \%$ increase in construction cost are necessary. At the other end of the scale, with the all-HY ship, both increases are but half as great. These numbers seem to suggest that, in particular, it is the deadweight carrier that would be most adversely affected by any excessive requirement for stiffness. This is just the vessel most likely to have a large length/depth ratio which makes it most likely to be hampered by the stiffness limits currently imposed.

\section{Strength Deck Location}

From Figure 4, the order of mganitude gain in performance inherent in the deep and narrow ship variant is clear, even though those particular performance norm curves were not the ultimate in refinement and not all gains (such as due to optimized frame spacing) made evident.

In the same general category of interest is a variable location of the strength deck, covered in Figure 9. In the investigations up to this point the upper deck was taken as the strength deck. In contrast to that, the figure shows the effect of transposing the strength deck one deck lower and making the upper deck and tween deck side shell as light as possible (but of medium steel).

Among the natural questions this plot is addressed to is ; How much weight in compensating structure can be afforded in order to make the upper deck an effective member in carrying longitudinal hull bending, despite the interruptions of large upper side shell openings, say? A rough answer in this length/depth range is that the two hull girders are roughly equivalent in weight and cost until the superstructure is added to the lowered strength deck version.

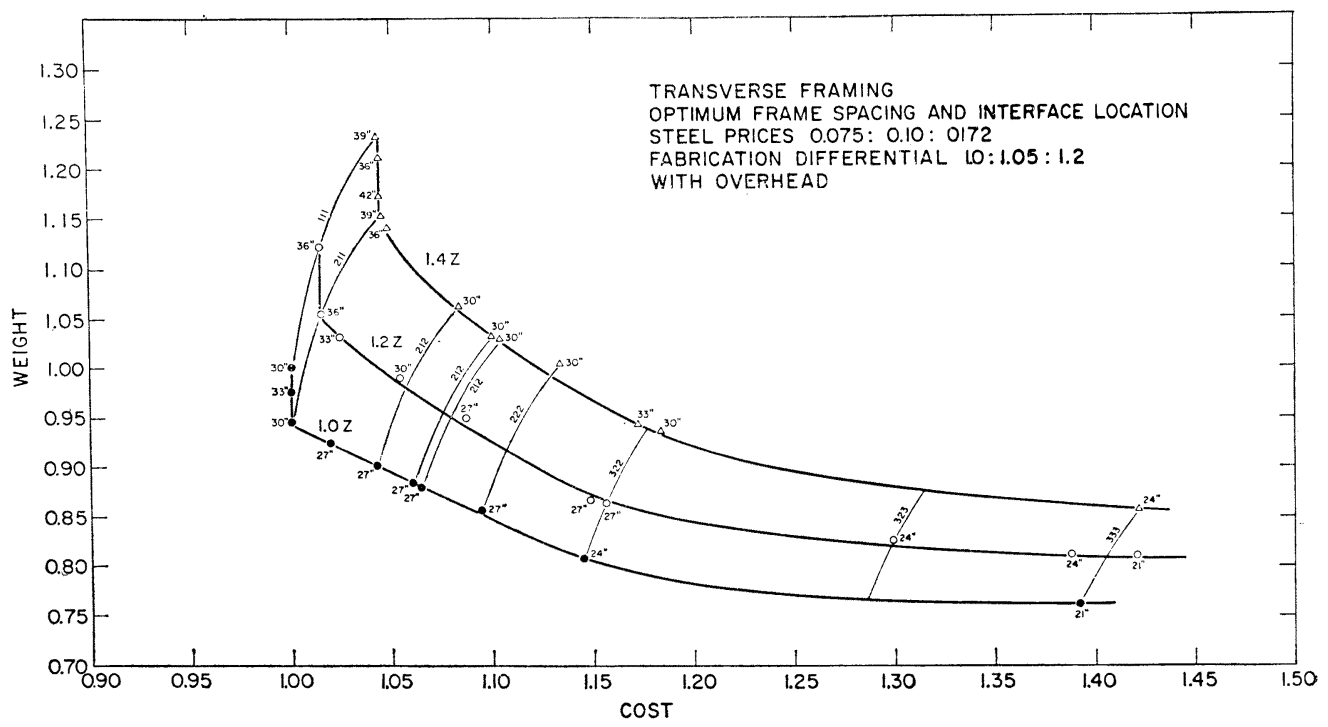

Fig. 8 


\begin{tabular}{lll} 
特 別 講 $\quad$ 演 \\
\hline
\end{tabular}

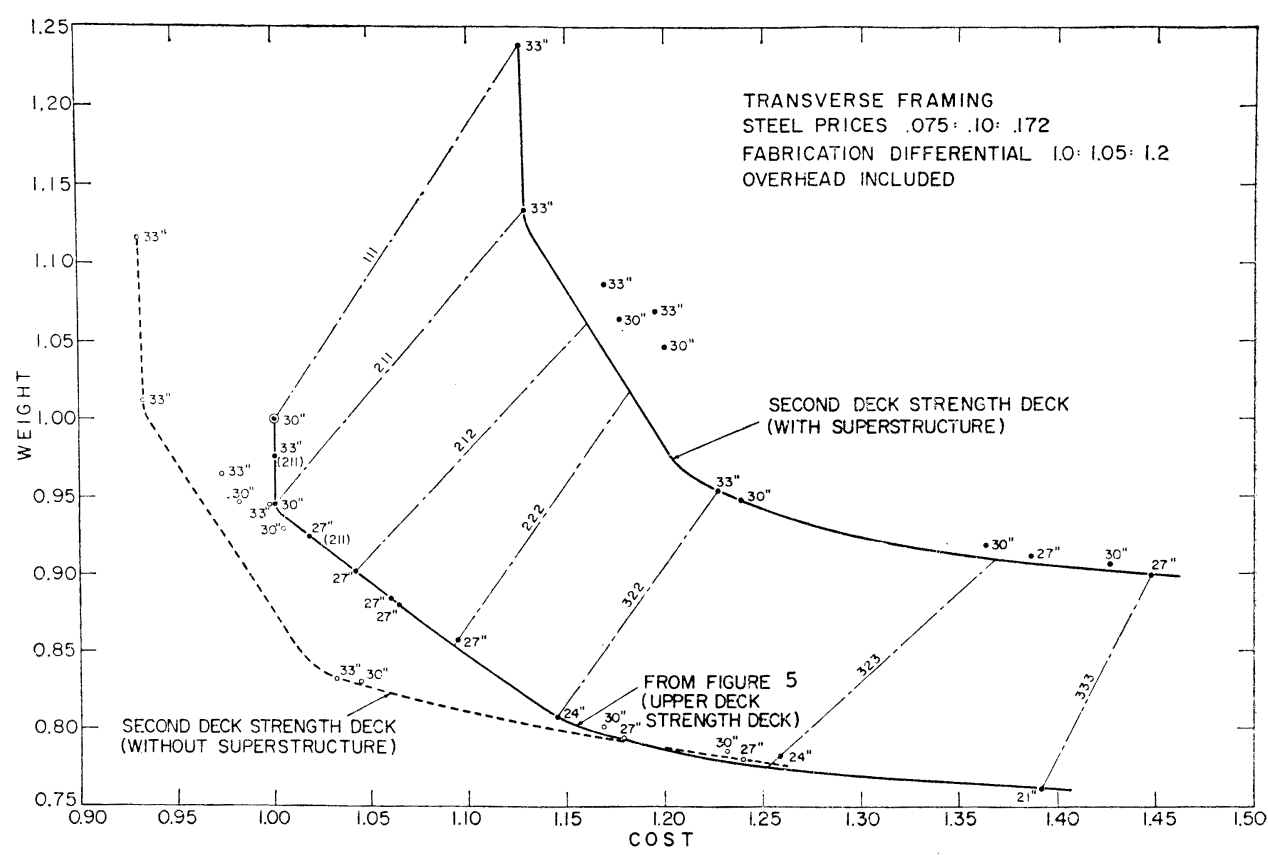

Fig. 9

\section{Other Materials than Steel-Real and Yet to Come}

The motivation for a look at materials other than steel was curiosity as to the importance of the part played by the modulus of elasticity. With one or two real materials, such as aluminum, in mind for guidance, a matrix of sixteen hypethetical materials was envisioned, each characterised by its modulus and yield (or ultimate) strength. Modulus values ranged from $10 \times 10^{6}$ psi to $40 \times 10^{6}$ psi in increments of $10 \times 10^{6} \mathrm{psi}$. Yield strength values were from $30 \times 30^{3}$ psi to $150 \times 10^{3} \mathrm{psi}$ in increments of $40 \times 10^{3}$ psi. For convenience, the ultimate strength was assumed to be twice the yield strength so that interpolation may be accomplished easily, whichever is used in establishing allowables stresses. Actually, all design stresses in this particular study were a function of the mean between yield and ultimate strength so the actual ratio between them is unimportant once stated. Then any combination of strength values can be used to enter the Figure at an "equivalent" $\sigma_{y}$.

For a transverse framing system, the outcome is shown in Figure 10 along with the performance norm for steels from Figure 5. For convenience and to bring order to the array of weight-cost curves, a reference grid has been overlaid connecting all points with a common frame spacing of $21^{\prime \prime}$. This frame spacing may or may not be optimal and, in general, it is not. In fact, the optimal frame spacing cannot be absolutely identified for any of the curves without some knowledge of the characteristics of the service the ship will be engaged in.

The unit weights, unit costs and the fabrication differential used were those for medium steel. It should be noted that the criteria for all transverse structure were reevaluated so that the transverse and longitudinal structures are made up of the same material whatever its unique properties.

The "elbow" localizing the optimal frame spacing was sought in each instance. For lack of a better definition of the optimum solution, this was assumed to be at the $45^{\circ}$ slope tangent point. These are not, then, either the least weight or the lowest cost solutions but a compromise between them. It is evident at once that, within reasonabl limits of cost estimating accuracy, and if all else is non-variable, both weights the costs decrease with increasing strength and modulus of elasticity although the rate 


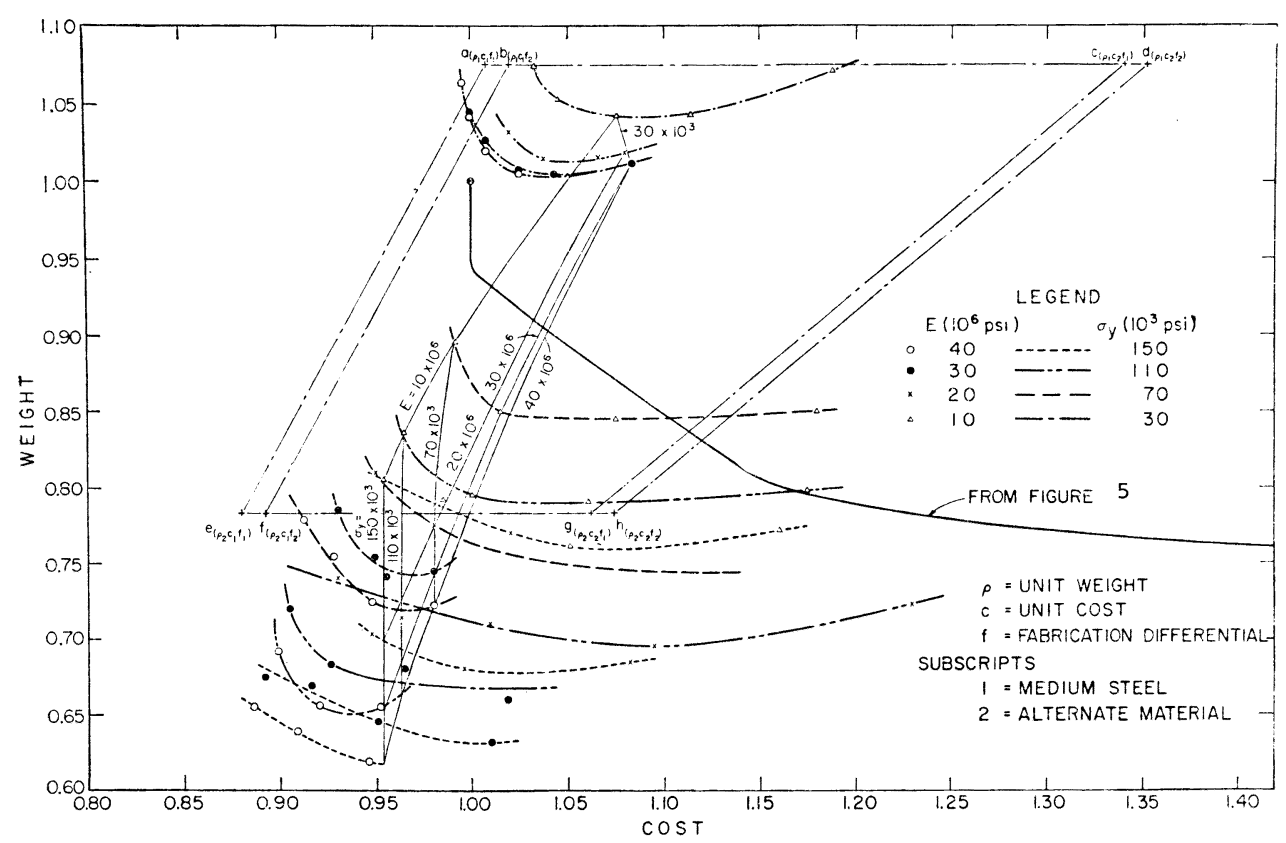

Fig. 10

of saving decreases toward the top of the strength and stiffness ranges.

The final assessment of a new material-real or hoped for-depends upon what is possible by way of achieving enhanced modulus and strength properties and whether these are worth the price in competition with steels; a judgement Figure 10 attempts to clarify. Notable also from the computer output is a large percentage of weight in transverse structure for high strength materials. This would seem to demand a change of framing system, if nothing else did.

The evidence that frame spacing should decrease with elastic modulus is no surprise but that it does not do so throughout with increasing strength of material may seem at first to be at variance with results for steels as exhibited in Figure 5. Making due allowance for the fact that the transverse framing is now of the same material as the longitudinally continuous structure and not universally of MS, the explanation is in the arbitrary definition adopted in this section for the presumed optimum solution. By comparsion with Figure 5, it is clear that there the performance norm representing the locus of optimum solution is approaching the horizontal in way of the high strength steels. This, in turn, is brought about by the real life price structure translating the high strength curves well to the right and into a higher price regime. Emphasis is therefore placed on the least weight solution which automatically calls for smaller frame spacings (at the high levels of strength).

Many of the plotted points would not satisfy present ABS standards of stiffness without the penalty of additional weight not considered here. Nevertheless, this factor is one which Figure 8 can help to compensate for.

Taking now a specific, real material, its unit weignt would be known as would its unit cost. Hopefully it would be possible also to develop some notion as to a reasonable fabrication differential. Beginning at point " $a$ " of Figure 10 (where only the strength and modulus are actually those for the real material) the transition to point " $h$ " (where all the properties are actual) can be traced by any of several paths as one after another of the characteristics is corrected; unit weight, unit cost and fabrication differential. After due allowance has been made for all these factors the illustration suggests that in this case, largely because of a considerable weight saving over medium steel, the alternative 
Table 3 Unified Weights and Costs for an Aluminum Allow Mariner

$$
\begin{aligned}
\sigma_{Y} & =19,000 \mathrm{psi} \\
\sigma_{\mathrm{u} 1 \mathrm{t}} & =35,000 \mathrm{psi}
\end{aligned}
$$

Unit weight $=0.096 \mathrm{lbs} / \mathrm{in}^{2}$

Unit cost, plates $=\$ 0.532 / 1 \mathrm{~b}$.

Unit cost, shapes $=\$ 0.625 / 1 \mathrm{~b}$.

\begin{tabular}{c|c|c|c|c|c|c}
\hline \hline \multirow{2}{*}{ Point } & \multicolumn{3}{|c|}{ Weights } & \multicolumn{2}{c}{ Costs } \\
\cline { 2 - 7 } & $\begin{array}{c}\text { Longitudinal } \\
\text { (tons/ft.) }\end{array}$ & $\begin{array}{c}\text { Transverse } \\
\text { (tons/ft. }\end{array}$ & $\begin{array}{c}\text { Total } \\
\text { (tons/ft.) }\end{array}$ & Ratio & $\begin{array}{c}\text { Total } \\
\text { (Dollars/ft.) }\end{array}$ & Ratio \\
\hline $\mathrm{a}$ & 7.63 & 1.457 & 9.087 & 1.457 & 3110.1 & 1.158 \\
$\mathrm{~b}$ & $\prime \prime$ & $\prime \prime$ & $\prime \prime$ & $\prime \prime$ & 3238.1 & 1.206 \\
$\mathrm{c}$ & $\prime \prime$ & $\prime \prime$ & $\prime \prime$ & $\prime \prime$ & 12672.6 & 4.720 \\
$\mathrm{~d}$ & $\prime \prime$ & $\prime \prime$ & $\prime \prime$ & $\prime \prime$ & 12800.6 & 4.768 \\
$\mathrm{e}$ & 2.59 & 0.494 & 3.084 & 0.495 & 2104.1 & 0.784 \\
$\mathrm{f}$ & $\prime \prime$ & $\prime \prime$ & $\prime \prime$ & $\prime \prime$ & 2232.2 & 0.831 \\
$\mathrm{~g}$ & $\prime \prime$ & $\prime \prime$ & $\prime \prime$ & $\prime \prime$ & 5348.0 & 1.992 \\
$\mathrm{~h}$ & $\prime \prime$ & $\prime \prime$ & $\prime \prime$ & $\prime \prime$ & 5476.0 & 2.040 \\
\hline
\end{tabular}

Steel Mariner values (As built, but derived by design program)

Weight 6.236 tons/ft. Cost 2684.7 Dollars/ft.

material is competitive with higher strength steel combination despite an apparent higher weight and cost initially.

The values for such points given in Table 3 are specifically for the properties of an aluminum alloy whose characteristics are given there also. (Unfortunately, the points lie off the scales chosen for Figure 10.) An extreme desire for weight saving (or some other over riding consideration) might justify such a choice of material but the cost penalty obviously would seem to be substantial. Furthermore, the weight advantage shown here would surely be decreased on account of stiffness limitations likely to be imposed by the classification societies. On the other hand, perhaps a higher strength alloy could be found which would be acceptable. The payoff is great for any increase of strength at such low levels.

\section{Closure}

Both a technique for helping to deal with the weight-cost compromise and the computer aided design tool are the primary subjects of this discussion. That these particualr means have already been used in industry with gratifying results is very rewarding.

The other message is in the Figures and the associated remarks are meant only to point up some of their salient features and to confirm understanding even through quantitative and significant conclusions from the Figures are sometimes qualitative and trivial in their statement. Although the results are strictly limited to the "Mariner" their implications are much broader. It is hoped that having raised such issues as hull girder stiffness, fabrication cost differentials, the potential for new materials and having implied the critical importance of cost estimating accuracy, others will be encouraged to add their efforts to resolve the questions.

Many refinements are possible. In fact, a computer aided synthesis program such as used in this undertaking, although necessary, can be considered suitable only for the first round in the design process, especially with the significant advances being made in computer usage for structural analysis. 


\section{References}

1. J.H.Evans, “A Structural Analysis and Design Integration”, Trans., SNAME, 1958, p. 244.

2. J.H.Evans and D. Khoushy, "Optimized Design of Midship Section Structure”, Trans., SNAME, 1963 , p. 144.

3. P. Rawat, "A Note on the Design Synthesis of Primary Ship Structure using Iterative Approach", Journal of Ship Research, Vol. 11, No. 2, June 1967, p. 123.

4. J. H. Evans, “Optimizing Hull Structural Design with High Strength Steel, ”SNAME Spring Meeting, Montreal, 1967, p. 1-1.

5. J.H.Evans, “Structural Performance Norms in Ship Design”, Trans. SNAME, 1970. 